\title{
The Impact of Covid-19 Pandemic on Leadership Development: A Study of Leaders in Jeddah, Saudi Arabia
}

\author{
James K. Siambi ${ }^{1}$ \\ ${ }^{1}$ School of Organizational Leadership, Pan Africa Christian University, Nairobi, Kenya \\ Correspondence: James K. Siambi, School of Management, School of Organizational Leadership, Pan Africa \\ Christian University, Nairobi, Kenya. E-mail: James.Siambi@students.pacuniversity.ac.ke
}

Received: January 5, 2022

doi:10.5539/ijbm.v17n3p85

\begin{abstract}
Covid-19 pandemic has influenced leadership development and possibly changed the perception of leadership learning. The closure of movements and gatherings during the pandemic effectively switched on virtual and digital alternatives to leadership development in attempts to fill the gap left by traditional approaches to leadership development. The effect of the Covid-19 pandemic on leadership ability to learn partially reflects the impact of educational technology and communication; however, it is not determined whether the impact is solely related to Covid-19 restrictions or the change of leadership development trends. The goals of this study highlight the plight of leadership development during the first year of Covid-19 pandemic which aim to inform future leadership training designs. This study uses a mixed method design, whose quantitative data focus on factual numerical details to confirm hypotheses while the qualitative data provides experiences based on concepts. The major study tool was a questionnaire, but the researcher made video calls to some participants for brief interviews. Video calls was preferred to enable the researchers to observe the respondents' behavior when explaining the impact of covid-19 in the organizations' leadership. The key findings postulate that most organizations were compelled to hold virtual leadership development sessions despite the ability to hold face to face small group development sessions. The instant shift to digital training exposed leaders to new possibilities in development and increased the number of training opportunities used by leaders. The significance of these findings inform future leadership development decisions on designing the leadership training and development.
\end{abstract}

Keywords: Covid-19, education, leadership development

\section{Introduction}

The covid-19 pandemic has led to a global crisis that has hit many sectors vehemently. The covid-19 pandemic has influenced leadership development and possibly changed the perception of leadership learning. In these demanding and chaotic Covid-19 pandemic times, the leaders' options are limited, and therefore work under restless pressure. This is due to the closure of movements and gatherings during the pandemic, firms effectively switched on virtual and digital alternatives to leadership development in attempts to fill the gap left by traditional approaches of leadership development. The impact of the Covid-19 pandemic on leadership development is significant. How leaders operate firms is key to the success of the organization. It is, therefore, vital to understand the leadership of firms, their coping strategies, and the need for government policies to respond to the impact of Covid-19. Some leaders have proposed targeted countermeasures for the pandemic (Darics, 2020). The effect of the Covid-19 pandemic on leadership ability to learn partially reflects the impact of educational technology. However, it is not determined whether the impact is solely related to Covid-19 restrictions or the change of leadership development trends. Leadership now exists in the twilight world unknown whether to wait for the return of normal service or forge ahead for some new normal that might offer continuity or stability of the policies (Sverdlik, Oreg \& Berson, 2019). The leadership developments are caught in an unfavorable position on being the pinch point in the system. This is because the leadership tends to rely on guidance about Covid-19 protocols, responses, procedures, and processes from the government health sector. As traditional approaches to leadership and the digitalization of leadership are decisive in the Covid-19 pandemic, the study develops a mixed-method design to investigate the impact of the pandemic on leadership development while exploring training design that best fit leadership development. The goals of this study highlight the plight of leadership development during the first year of the Covid-19 pandemic, which aims to inform future leadership training 
designs. We, therefore, hypothesize that leadership development requires adopting a virtual work environment to fill the gap left by traditional approaches in the mid of the Covid-19 pandemic. In this context, to explore the impact of Covid-19 on leadership development in Jeddah and suggest the appropriate training methods to deal with the pandemic, we investigated leaders in the different firms in Jeddah Saudi Arabia. The purpose of the research was to investigate the impact of Covid-19 on leadership and inform future leadership development decisions on designing the leadership training and development.

\section{Literature Review}

The literature review indicated that leadership researches conducted in several service contexts fundamentally are in the non-virtual work environment (Muganda \& Pillay (2013). According to Darics, (2020), most of the researches also were conducted in non-crisis situations hence the outbreak of the Covid-19 crisis that introduced new normal of virtual working has insufficient information. The process and behavior relating to leading virtual teams have not been sufficiently investigated thus there is little information associated with virtual leadership training (Newman et al., 2020). Muganda \& Pillay (2013) studied work satisfaction, team effectiveness, and different forms of leadership applicable to virtual team building and training. There is a significant research gap to provide information on the efficacy of leadership in service employment, especially during a crisis (Jenster \& Steiler, 2011)

Stoker, Garretsen, \& Soudis, (2019) provided some insightful information on virtual leadership in manufacturing and financial institutions. The research was carried out based on the 2008 financial crisis that affected these industries severely. The study indicated that these industries experience increased directive leadership and less participative leadership behavior, especially in crises. The finding from this research emphasizes the relevance of task-oriented behavior during the crisis but fails to provide any indication of their effectiveness (Stoker, Garretsen, \& Soudis, 2019). Employees fear the extreme consequences of virtual leadership training and working environment as a result of crises or pandemics such as Covid-19 that has hit the world economy (Fernandez et al., 2021). It is paramount to have intensive research that provides sufficient information on the leadership context. Organizational leadership needs to have an understanding in diverse ways that can be adopted such as transforming to virtual work arrangements that can help the company to continue with its operations when there is an unexpected crisis such as the Covid-19 pandemic (Darics, 2020).

Virtual leadership should create a work environment that is a task and relation-oriented behavior that are fundamental in overcoming the challenges associated with a virtual work environment (Liao, 2017). Virtual leadership should address issues such as employees' hardships systematically through adopting and understanding viable means to accomplish the task collectively (Alward \& Phelps, 2019). The management should initiate virtual task-oriented leadership behavior that majors on attaining organizational goals through giving a clear task objective and monitoring work progress(Worley et al., 2020). Virtual relation-oriented leadership should focus on promoting collaborative interactions among the employees through creating a virtual supportive climate(Agarwal et al., 2020). Both task and relation orientation meta-categories should incorporate behaviors relevant in a virtual working environment which include specification of online team structures for task-orientation and team building activities that promote personal interactions among the member which is crucial for relation-orientation (Liao, 2017). Covid-19 pandemic gives the organizational management team an additional mandate to ensure that employees maintain both task and relation-oriented behaviors in a virtual working environment(Han et al., 2020). By so doing, organizational leadership ensures that the operations are not severely affected by the pandemic.

Virtual leadership has a significant influence on both individuals and team-related process factors which fundamentally affects inputs and output(Graham \& Daniel, 2021). The emotional factors surrounding individual and team members due to tension of changes that come with virtual leadership, and behavioral factors due to independence and team cohesiveness are some of the major issues that affect virtual leadership(Angelo \& McCarthy, 2020). Employees exposed to Covid-19 have higher chances of suffering emotionally, which subsequently affect their working and living condition(Daraba et al., 2021). The regulations and protocols laid by WHO such as social distancing and staying home significantly affect relation-oriented behaviors since employees cannot extend interpersonal relations and welfare support to the victims(Bartsch et al., 2021). A lot of perceived insecurity and tension contribute to behavioral changes thus affecting performances as individuals and as a team(Mercedes \& Burrell, 2021). Virtual leadership is responsible to ensure that relations-oriented behaviors are achieved even without face-to-face meetings(Rohwer et al., 2020). Virtual leaders should think of different ways of keeping interpersonal relations without physical meetings(Palese \& Schmid Mast, 2020). 


\section{Method}

For this study, a mixed-method design was used. The qualitative approach was used in the study to provide experiences based on concepts regarding the impact of Covid-19 on leadership development while the quantitative approach was used in the research to focus on factual numerical details to confirm hypotheses. Video call interviews were used as the main method of gathering qualitative data as the researchers observed the behavior of the respondents. The numbers of the participants were determined by the research question and the availability of the leaders. It is worth noting that the number of leaders may be few in firm and increase in another firm.

The key purpose of the survey was to find out the impact of Covid-19 on leadership development in Jeddah Saudi Arabia. The data was collected from leaders in different firms during the lockdown when the organizations had to change to the virtual work environment. The calculation of sample size was done based on the formula given:

Sample size $=\sigma^{2} z^{2} / E^{2}$ where $z=1.96$ is the level of confidence; $E=0.05$ is the margin of error, and $\sigma=0.5$.

The estimated sample size based on the given parameters was 384 . Nonetheless, to improve the data reliability the sample was increased to 553. However,29 participants from the sample were excluded. Thus the sample from the survey included 524 firms in Jeddah that the government has published depending on their industrial features as well as their sizes. The firms from which leaders participated included information technology, manufacturing, real estate, commercial industry, and finance. Most of the leaders who participated in the survey had switched to the virtual work environment or were anticipating adopting the virtual work environment

The research used measures as validated in the previous studies and explicitly referred to Covid-19 induced context of work. The development of the questionnaire as the instrument was based on the previous studies that were carried out in Saudi Arabia. The target respondents included leaders in established firms. The questions were customized to ensure that the participants answered according to the impact felt in the respective firm as a result of Covid-19 outbreak. The pilot was carried out among firm owners with an aim of refining and fine-tuning the questionnaire to ensure reliability and validity. The questionnaire was revised based on the feedback from the respondents who participated in the pilot study. As a result, the final questionnaire consisted of 17 easy to answer questions and were distributed to leaders in firms in four categories that included three sets of questions on demographic features, six set of questions on the pandemic impact on leadership development on leaders' perception about the changes due to Covid-19 pandemic. The researcher collected data via an online survey platform from leaders in a virtual working environment, however; the leaders were contacted via telephone to invite them to answer the self-administered questionnaire.

The collected data from anonymous leaders was entered in excel for interpretation and analysis. SPSS was used to analyze data. 29 participants from the sample were excluded, as they did not meet the minimum threshold of the questions that they answered. The descriptive statistics of samples, demographic features and each question was used to summarize the data.

\section{Results}

The demographic characteristic of the research included different economic sectors in Jeddah, Saudi Arabia. The research had an effective response of $94.8 \%$ (524/553) respondents that were used as a sample. Various industries in Jeddah, Saudi Arabia in the effective response investigation included information technology, manufacturing, finance, real estate, and service and commercial industries. Manufacturing has the largest percentage of $34.6 \%$. IT held the second position with $18 \%$. Service and commercial industries have $23.7 \%$ while finance had $12.4 \%$. Real estate accounted for $6.7 \%$ and the rest, which was $4.8 \%$, included other industries. The distribution was under Jeddah industrial characteristics. A balanced number of firms were used for the research with 141 companies (26.9\%) having 50 employees and below. $162(30.1 \%)$ had 50 to 500 employees. 129 organizations (24.4\%) had between 501 to 5000 employees. 29 firms (17.6\%) had 5000 and above employees.

The research also sought to determine the impact of the Covid-19 pandemic on leadership in firm operations. About $50 \%$ of organizations maintained their operations reporting overall stability. However, a significant number of firms stopped operations or were closed due to various reasons such as shortage of raw materials and stock-outs due to lockdown. Firms across all the industries were facing employees' salary and social insurance pressure, loss of orders, delays in making payment to suppliers, inability to settle loans, or inability to pay rent especially for firms with less than 50 employees. The majority of the leaders admitted that firms did not maintain production due to a shortage of materials and lack of adequate supplies. Most domestic customers canceled 
orders from $22.9 \%$ of organizations surveyed. $63.9 \%$ of leaders believed that firms had international orders canceled or delayed supplies.

About $2.86 \%$ of leaders in Jeddah, Saudi Arabia had devoted effort to research, development, and innovations before the outbreak of Covid-19. Unfortunately, the outbreak of Covid-19 hindered the launching of new products and also affected the progress of the projects in various firms within different institutions mainly in the information technology industry. Most organizations leadership were faced with increased labor cost and the need to invest heavily in technology to facilitate virtual working. The increased cost forced most of the firm leaders to reduce the number of employees, reduce the wage rate, and postpone the recruitment process. About $16.79 \%$ of the manufacturing industries in Jeddah, Saudi Arabia faced the biggest challenge in employment difficulties. Most leaders in firms changed their operations to a virtual working environment with most of the leaders across all industries working remotely or planning to do so by adopting digital operations. Although virtual leadership had the responsibility to ensure that employees working remotely do not compromise the task and relations orientations, they lacked sufficient information on the best training approach that would help in fulfilling this task. Virtual leadership should use due diligence when dealing with the employees working virtually to curb the emotional and behavioral impacts of working online.

Table 1. The impact of Covid-19 on leadership development in Jeddah, Saudi Arabia firms

\begin{tabular}{|c|c|c|c|}
\hline Leaders & Field of business & $\begin{array}{l}\text { No. of leaders in } \\
\text { Firms }\end{array}$ & Percentage \\
\hline Industry & Sub-industry & & \\
\hline & / Software and hardware services / E-commerce / Internet & & \\
\hline IT & operations & 94 & $17.94 \%$ \\
\hline \multirow[t]{13}{*}{ Manufacture } & Main Manufacture & 88 & $16.79 \%$ \\
\hline & Electronic technologies / Semiconductors / Integrated circuits & 14 & $2.67 \%$ \\
\hline & Clothing / Textiles / Leather & 7 & $1.34 \%$ \\
\hline & Aerospace / Aviation / Energy / Chemical & 10 & $1.91 \%$ \\
\hline & Machinery / Equipment / Heavy industry & 10 & $1.91 \%$ \\
\hline & Electric appliances & 5 & $0.95 \%$ \\
\hline & Furniture / Crafts / Toys & 6 & $1.15 \%$ \\
\hline & FMCG (food / beverage / cosmetics) & 12 & $2.29 \%$ \\
\hline & Automobiles and spare parts & 9 & $1.72 \%$ \\
\hline & Medical / Nursing / Health / Sanitation & 8 & $1.53 \%$ \\
\hline & Instrumentation / Industrial Automation & 5 & $0.95 \%$ \\
\hline & Pharmaceutical / Bioengineering / Medical Equipment & 15 & $2.86 \%$ \\
\hline & & 181 & $34.60 \%$ \\
\hline \multirow[t]{12}{*}{ Service and Commercial } & Publishing / Printing / Packaging & 5 & $0.95 \%$ \\
\hline & Advertising / PR / Media / Art & 4 & $0.76 \%$ \\
\hline & Law & 1 & $0.19 \%$ \\
\hline & Accounting / Auditing & 1 & $0.19 \%$ \\
\hline & Traffic / Transportation / Logistics & 11 & $2.10 \%$ \\
\hline & Education / Training / Scientific research / Colleges & 15 & $2.86 \%$ \\
\hline & Trading / Import \& Export & 13 & $2.48 \%$ \\
\hline & Wholesale / Retail & 13 & $2.48 \%$ \\
\hline & Communication / Telecommunications / Network equipment & 21 & $4.01 \%$ \\
\hline & Property Management / Commercial Centers & 8 & $1.53 \%$ \\
\hline & Agency / Consulting / Headhunting / Certification & 12 & $2.29 \%$ \\
\hline & & 124 & $23.70 \%$ \\
\hline Finance & Bank / Insurance / Securities / Investment Bank / Risk Fund & 65 & $12.40 \%$ \\
\hline \multicolumn{4}{|c|}{ 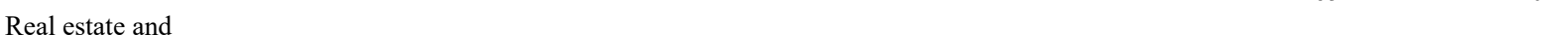 } \\
\hline Architecture & Real estate development / Architectural engineering / Design & 35 & $6.68 \%$ \\
\hline \multirow[t]{10}{*}{ Other industry } & & 25 & $4.77 \%$ \\
\hline & Employees & & \\
\hline & 50 and below & 141 & $26.91 \%$ \\
\hline & $51-100$ & 54 & $10.31 \%$ \\
\hline & $101-300$ & 71 & $13.55 \%$ \\
\hline & $301-500$ & 37 & $7.06 \%$ \\
\hline & $501-1000$ & 42 & $8.02 \%$ \\
\hline & $1001-4999$ & 87 & $16.60 \%$ \\
\hline & 5000 and above & 92 & $17.56 \%$ \\
\hline & Total & 524 & $100 \%$ \\
\hline
\end{tabular}


The gap in virtual leadership training results in negative expectations since most organizations in different industries anticipated financial losses during the first year of the Covid-19 pandemic. Throughout Jeddah, Saudi Arabia, only a few companies were positive about virtual leadership with the respondents expecting to realize some profits. An organization with numerous employees (1000 and above) had higher chances of embracing virtual leadership training that would facilitate survival, which subsequently would help the leaders to realize some profits and have adequate cash flows to ensure that operations are not severely affected by the covid-19 pandemic. Jeddah industries that adopted virtual leadership training expected the government to reduce, exempt, or rescheduled VAT, income tax, and social insurance among other expenditures. Virtual leaderships in vast companies in different fields in Jeddah, Saudi Arabia expect the government to stipulate consumption, provide subsidies such as rents, utilities among others.

Although half of the firms maintained stability in operations, half of them stopped their operations for various shortages as seen from question 1 and 2 responses. Firms confirmed that they were experiencing social insurance and workers' salary issues as seen for question 3 responses. From the responses in question 4 , it was confirmed that most firms in production faced shortage of materials.

\section{Discussion}

Although the study examining the impact of Covid-19 on leadership development in the context of virtual working environment, there was no change of leadership, development trends dealt with the effective leadership in unpredictable transformation like the crisis of the Covid-19 pandemic (Bartsch et al., 2021). As a result, this study contributes to the scarce literature on leadership development in firms during the Covid-19 crisis. The study focused on the changes in the leadership trends due to Covid-19 pandemic. The results support that the pandemic has affected the leadership development in Jeddah as policymaking relies on the virtual meeting. It is worth noting that the studies analyzed the impact of leadership development in some firms and more comprehensively reflected on the impact of Covid 9 on leadership.

Given the Covid-19 pandemic, the virtual work environment was not the same as having traditional meetings. Most of the firms were facing leadership challenges and some of them said they hardly met (Carte \& Becker, 2017). Through the research regarding the training of leadership in virtual environments, most leaders admitted facing challenges in making policies due to lack of meeting platforms. Other leaders admitted that the virtual meetings were regularly canceled due to lack of internet connection or power interruption on an ongoing virtual meeting. as a result, the launching of new products and the progress of the projects in various firms within institutions principally in the information technology industry were greatly affected (Cascio \& Montealegre, 2016). Many leaders also responded that the virtual work environment has caused them not to be effective in the contribution to leadership skills. Leaders also felt that a virtual work environment in an attempt to follow the Covid-19 directives has increased the operating cost due to the overreliance on the internet thus leading to delayed delivery of services or communication effectiveness. The increased cost forced most of the leaders to reduce the number of workers, reduce the wage rate, and postpone the recruitment process in firms (Battilana, Gilmartin, Sengul, Pache, \& Alexander, 2010). The interviewed leaders reported that the leadership development logistics were significantly affected by the Covid-19 pandemic situation in various ways. Since the Covid-19 pandemic has spread globally, all businesses have been affected in one way or another, leaders admitted that the operation in the firms is affected.

The leaders, however, deliberated that the pandemic has impacted the technological innovation, workers as well as leadership development in some firms. For instance, the epidemic has delayed the launching of recruits, projects launching, and new products in some firms. The combination of the Covid-19 pandemic and the leadership development trends prompted many firms to recognize the challenges as well as to devote themselves to the innovation efforts. Many leaders believed that the pandemic has promoted the establishment of remote recruitment, offices, and business negotiation models to respond to the crisis. Various leaders mentioned that the Covid-19 pandemic had a positive impact on leadership development as some competitions were eliminated to some extent due to the launching of new business and acceleration of changes in the marketing method. For instance, the textile industries have been adopted retailing in large shopping malls. During the Covid-19 pandemic, most workers were transferred from offline stores to online stores as the sales teams. As a result, the leaders of firms who completed the channel transformation have survived well in the crisis through the use of social media and live streaming (Eubanks, Palanski, Olabisi, Joinson \& Dove, 2016). The Covid-19 pandemic has somehow strengthened the determination of some leaders to turn crisis into investment and opportunities. Similarly, the crisis has strengthened the awareness of consumers and changed the clients' behaviors. Some leaders reported that their firms have driven reforms in the strategies of marketing. The respondents also indicated that there is a dire need to accelerate the development of a virtual work environment. Some leaders 
have changed the store-based mode of marketing and integrated interacting channels of marketing (Behrendt, Matz \& Göritz, 2017). For instance, the stores not being open but the sales team conduct live broadcast, social media marketing among other platforms. The finding of the research shows that the leadership development was not rebound. Leadership is determined by the ability to lead the workers. Since the pandemic seems to be persistent, almost all firms believe they will incur losses at some point.

\section{Conclusion}

The outbreak of Covid-19 has resulted in enormous changes in almost every area of the human sphere. Leadership in Jeddah, Saudi Arabia has not been exceptional as the management from different industries adopt new ways to keep the firms running despite the introduction of new rules and protocols demanded to control the menace. One of the issues that struck management is the cessation of movement due to lockdowns, which calls for leaders to adopt virtual and digital operations. Although a significant number of organizations in Jeddah, Saudi Arabia had information on virtual leadership that helped them to maintained stability in the first year of Covid-19, a great number of firms lacked sufficient information on virtual leadership. Insufficient information on virtual leadership adversely affected the operations with most organizations closing down. All leaders throughout Jeddah, Saudi Arabia major economic fields accepted the introduction of virtual leadership training since it is the only means to ensure that organizations continue as usual in the future in case of an outbreak of a pandemic or any other eventuality that can limit in-person services.

The Jeddah community, like most parts of the world, experiences an information gap in the area of virtual leadership training. Most of the leaders in key industries in Jeddah are not conversant with virtual leadership and other digital activities, which create a management problem in times of pandemics such as Covid-19, which demand operations to be carried out remotely.

\section{Recommendations}

Virtual leadership should create a work environment that is a task and relation-oriented behaviors that are fundamental in overcoming the challenges associated with a virtual work environment. Effective virtual leadership training must be able to maintain both task and relation-oriented environments to ensure employees' wellbeing and interpersonal relations without necessarily meeting physically. Virtual leadership training should emphasize online communication to ease tension and other emotional challenges faced by the employees working remotely. Based on the survey on leaders appealing for government support, it would be of great help if financial policies would be put in place to help the firm to survive. Some leaders felt that the financial policies needed to be put in place to support the operation of the firm in the virtual work environment. Leaders expect measure ad public policies such as tax exemption to help the first to survive in the difficult times of the Covid-19 pandemic while gradually adopting the virtual operations. The investment driving the leadership development plays a driving role in promoting firms operations. Therefore, the measures supporting the virtual work environment should be put in place policies targeted to leadership development in Covid-19 crisis. The roles of industry leaders are to promote smooth operations. The roles of leaders in promoting the work environment can be done through facilitating an online-integrated work environment such as policy stimulations and strengthening of online services.

\section{Acknowledgments}

The researcher could not accomplish this work without the exceptional assistance of numerous leaders in different firms in data collections. Most importantly, the anonymous participants offered great insights in learning the impact of Covid-19 on leadership development that they share selflessly. The author affirms no conflict of interest in any way whatsoever. There was no role played by any funders in the study design, data collection analysis, or interpretation. Moreover, there are no third-party roles in the writing or publishing of the results. The author confirms to solely develop the hypotheses of the study, collect data from various sources, analyze and interpret result findings, and prepare the report from the study that can be used for further study.

The research did not receive any funds.

\section{References}

Agarwal, S., Sabadia, S., Abou-Fayssal, N., Kurzweil, A., Balcer, L. J., \& Galetta, S. L. (2020). Training in neurology: Flexibility and adaptability of a neurology training program at the epicenter of COVID-19. Neurology, 94(24), e2608-e2614. http://doi.org/10.1212/wnl.0000000000009675

Alward, E., \& Phelps, Y. (2019). Impactful leadership traits of virtual leaders in higher education. Online Learning, 23(3). http://doi.org/10.24059/olj.v23i3.2113 
Anderson, T. C. (2020). Academics, Achievement Gap, and Nutritional Health: The Impact of Coronavirus on Education. Delta Kappa Gamma Bulletin.

Angelo, R., \& McCarthy, R. (2020). A pedagogy to develop effective virtual teams. Journal of Computer Information Systems, 1-8. http://doi.org/10.1080/08874417.2020.1717396

Bartsch, S., Weber, E., Büttgen, M., \& Huber, A. (2020). Leadership matters in crisis-induced digital transformation: How to lead service employees effectively during the COVID-19 pandemic. Journal of Service Management, 32(1), 71-85. http://doi.org/10.1108/josm-05-2020-0160

Battilana, J., Gilmartin, M., Sengul, M., Pache, A., \& Alexander, J. A. (2010). Leadership competencies for implementing planned organizational change. The Leadership Quarterly, 21(3), 422-438. http://doi.org/10.1016/j.leaqua.2010.03.007

Behrendt, P., Matz, S., \& Göritz, A. S. (2017). An integrative model of leadership behavior. The Leadership Quarterly, 28(1), 229-244. http://doi.org/10.1016/j.leaqua.2016.08.002

Carte, T., \& Becker, A. (2017). Emergent leadership in self-managed virtual teams: A replication. AIS Transactions on Replication Research, 3, 1-12. http://doi.org/10.17705/1 atrr.00020

Cascio, W. F., \& Montealegre, R. (2016). How technology is changing work and organizations. Annual Review of Organizational Psychology and Organizational Behavior, 3(1), 349-375. http://doi.org/10.1146/annurev-orgpsych-041015-062352

Daraba, D., Wirawan, H., Salam, R., \& Faisal, M. (2021). Working from home during the corona pandemic: Investigating the role of authentic leadership, psychological capital, and gender on employee performance. Cogent Business \& Management, 8(1), 1885573. http://doi.org/10.1080/23311975.2021.1885573

Darics, E. (2017). E-leadership or "How to be boss in instant messaging?" the role of nonverbal communication. International Journal of Business Communication, 57(1), 3-29. http://doi.org/10.1177/2329488416685068

Eubanks, D. L., Palanski, M., Olabisi, J., Joinson, A., \& Dove, J. (2016). Team dynamics in virtual, partially distributed teams: Optimal role fulfillment. Computers in Human Behavior, 61, 556-568. http://doi.org/10.1016/j.chb.2016.03.035

Fernandez, C. S., Green, M. A., Noble, C. C., Brandert, K., Donnald, K., Walker, M. R., ... Corbie-Smith, G. (2021). Training "Pivots" from the pandemic: Lessons learned transitioning from in-person to virtual synchronous training in the clinical scholars leadership program. Journal of Healthcare Leadership, 13, 63-75. http://doi.org/10.2147/jhl.s282881

Graham, C., \& Daniel, H. (2021). Fault lines in virtual team leadership and team performance in undergraduate virtual team short-term projects. International Journal of e-Collaboration, 17(1), 1-14. http://doi.org/10.4018/ijec.2021010101

Han, S. J., Kim, M., Beyerlein, M., \& DeRosa, D. (2020). Leadership role effectiveness as a mediator of team performance in new product development virtual teams. Journal of Leadership Studies, 13(4), 20-36. http://doi.org/10.1002/jls.21677

Jenster, N. P., \& Steiler, D. (2011). 'Turning up the volume' in inter-personal leadership: Motivating and building cohesive global virtual teams during times of economic crisis. Advances in Global Leadership, 267-297. http://doi.org/10.1108/s1535-1203(2011)0000006014

Liao, C. (2017). Leadership in virtual teams: A multilevel perspective. Human Resource Management Review, 27(4), 648-659. http://doi.org/10.1016/j.hrmr.2016.12.010

Mercedes, D., \& Burrell, D. N. (2021). Managerial adaptability and business strategic change in age of COVID-19. PSU Research Review, ahead-of-print(ahead-of-print). http://doi.org/10.1108/prr-12-2020-0046

Muganda, N., \& Pillay, K. (2013). Forms of power, politics and leadership in asynchronous virtual project environment. International Journal of Managing Projects in Business, 6(3), 457-484. http://doi.org/10.1108/ijmpb-11-2011-0075

Newman, S. A., Ford, R. C., \& Marshall, G. W. (2019). Virtual team leader communication: Employee perception and organizational reality. International Journal of Business Communication, 57(4), 452-473. http://doi.org/10.1177/2329488419829895

Palese, T., \& Schmid Mast, M. (2020). The role of social categorization and social dominance orientation in behavioral adaptability. Journal of Personality and Social Psychology. http://doi.org/10.1037/pspi0000351 
Rohwer, E., Kordsmeyer, A., Harth, V., \& Mache, S. (2020). Boundarylessness and sleep quality among virtual team members - a pilot study from Germany. http://doi.org/10.21203/rs.3.rs-24024/v2

Stoker, J. I., Garretsen, H., \& Soudis, D. (2019). Tightening the leash after a threat: A multi-level event study on leadership behavior following the financial crisis. The Leadership Quarterly, 30(2), 199-214. http://doi.org/10.1016/j.leaqua.2018.08.004

Sverdlik, N., Oreg, S., \& Berson, Y. (2019). When do leaders initiate changes? The roles of coping style and organization members' stability-emphasizing values. Applied Psychology, 69(4), 1338-1360. http://doi.org/10.1111/apps.12224

Uhl-Bien, M., \& Arena, M. (2018). Leadership for organizational adaptability: A theoretical synthesis and integrative framework. The Leadership Quarterly, 29(1), 89-104. http://doi.org/10.1016/j.leaqua.2017.12.009

Worley, C. B., LoSavio, S. T., Aajmain, S., Rosen, C., Stirman, S. W., \& Sloan, D. M. (2020). Training during a pandemic: Successes, challenges, and practical guidance from a virtual facilitated learning collaborative training program for written exposure therapy. Journal of Traumatic Stress, 33(5), 634-642. http://doi.org/10.1002/jts.22589

\section{Copyrights}

Copyright for this article is retained by the author(s), with first publication rights granted to the journal.

This is an open-access article distributed under the terms and conditions of the Creative Commons Attribution license (http://creativecommons.org/licenses/by/4.0/). 